\title{
Exame Nacional Do Ensino Médio: Como Utilizar No Planejamento Docente*
}

\author{
National High School Exam: How To Use In Teaching Planning
}

\author{
Jonathas Ieggli da Silva \\ Universidade Luterana do Brasil (ULBRA) \\ Ursula Tatiana Timm \\ Universidade Luterana do Brasil (ULBRA) \\ Claudia Lisete Oliveira Groenwald \\ Universidade Luterana do Brasil (ULBRA)
}

\begin{abstract}
Resumo
Este artigo tem por objetivo analisar as questões das provas de Matemática e suas Tecnologias do Exame Nacional do Ensino Médio (Enem), realizadas nos anos de 2016 e 2017, classificando-as em suas respectivas competências conforme a matriz de referência da área de Matemática e suas Tecnologias. Buscou-se recursos tecnológicos, que possam ser incluídos no planejamento didático de professores de Matemática para resolução das questões do Enem. Esses recursos podem ser explorados em uma perspectiva que possibilite o protagonismo dos estudantes, possibilitando que tirem conclusões e ampliem sua percepção em relação a Matemática, desenvolvendo o pensamento matemático de forma mais dinâmica. Os conteúdos que foram contemplados nas provas em 2016 e 2017 foram: Geometria Plana e Espacial, Porcentagem, Regra de três, Interpretação de gráficos ou tabelas para resolução ou fazer inferências, Estatística, Variação de grandezas (direta ou inversamente), Raciocínio Lógico, Análise Combinatória, Funções, Probabilidade, Logaritmo, Progressão Aritmética, Razão, Escala e Conversão de Unidades e Matemática Financeira. Ao resolver as questões de funções pode-se observar que a incorporação do software GeoGebra pode ser um recurso dinâmico para o esboço de gráficos, transformações de funções e análise de parâmetros das mesmas. No conteúdo de Geometria Plana e Espacial o mesmo software foi utilizado para visualização e compreensão de áreas, volumes e planificações.
\end{abstract}

Palavras chave: Matemática; Enem; Ensino Médio; Recursos Tecnológicos

\begin{abstract}
The aim of this article is to analyze the Mathematics tests and their National High School Examination Technologies (Enem), carried out in the years 2016 and 2017, classifying them in their respective competences according to the reference matrix of Mathematics and their Technologies. We sought technological resources that could be included in the didactic planning of Mathematics teachers to solve the Enem's questions. These resources can be explored in a perspective that allows the protagonism of students, allowing them to draw conclusions and broaden their perception in relation to mathematics, developing mathematical thinking more dynamically. The contents that were considered in the tests in 2016 and 2017 were: Geometry and Space, Percentage, Rule of three, Interpretation of graphs or tables to solve or make inferences, Statistics, Variation of quantities (directly or inversely), Logical Reasoning, Analysis Combinatorial, Functions, Probability, Logarithm, Arithmetic Progression, Reason, Scale and Unit Conversion and Financial Mathematics. When solving the questions of
\end{abstract}

* Pesquisa financiada pelo CNPq. 
functions it can be observed that the incorporation of GeoGebra software can be a dynamic resource for the sketch of graphs, transformations of functions and analysis of the same of the same ones. In the contents of Plane and Spatial Geometry the software was used for visualization and comprehension of areas, volumes and planning.

Keywords: Math; Enem; High School; Technological resources

\section{Introdução}

O Exame Nacional do Ensino Médio (Enem), criado em 1998 pelo Instituto Nacional de Estudos e Pesquisas Educacionais Anísio Teixeira (Inep), do Ministério da Educação (MEC), é um exame individual e de caráter voluntário, oferecido anualmente aos concluintes e egressos do Ensino Médio, com o objetivo de avaliar o desempenho escolar e acadêmico ao fim da Educação Básica (INEP, 2005).

Até o ano de 2008, o Enem era constituído por uma prova contendo 63 questões, com uma proposta interdisciplinar e uma redação. Esta avaliação era realizada em apenas um dia. A partir de 2009, o Enem passou a exigir o conteúdo do Ensino Básico dividido em áreas do conhecimento, a saber: Ciências Humanas e suas Tecnologias; Ciências da Natureza e suas Tecnologias; Linguagens, Códigos e suas Tecnologias e Matemática e suas Tecnologias. Nesse ano, o exame passou a funcionar como instrumento de admissão a cursos superiores de universidades brasileiras, aumentando assim, o número de alunos inscritos em cada edição. No ano de 2016 foram 9,2 milhões de estudantes e em 2017 alcançou a marca de 7,6 milhões de estudantes.

A nota do Enem pode ser utilizada como critério de seleção para os estudantes que pretendem ingressar no Ensino Superior através de bolsas nos Programa Universidade para Todos (ProUni), de instituições particulares ou comunitárias, ou no Sistema de Seleção Unificada (Sisu), de instituições públicas. Além disso, cerca de 500 universidades do país já utilizam o resultado do Enem como critério de seleção para o ingresso no ensino superior, seja complementando ou substituindo o vestibular realizado nestas instituições.

Em 2009, o Enem passou a ser realizado em dois dias e a conter 180 questões, divididas nas áreas referidas, sendo 45 questões por área e, uma redação envolvendo temas da atualidade.

Considerando-se a importância do Enem, o interesse dos estudantes e o número crescente de inscritos, este artigo tem por objetivo apresentar uma análise da prova de Matemática e suas Tecnologias, buscando subsidiar os professores desta disciplina a utilizarem as questões da prova em seu planejamento docente. Neste sentido apresenta-se a classificação das questões abordadas nas provas de 2016 e 2017, apresentando como desenvolver tais 
questões utilizando Tecnologias da Informação e Comunicação (TIC).

As TIC fazem parte do cotidiano dos estudantes e podem ser exploradas pelos professores para aproximá-los do ambiente escolar buscando despertar o interesse e motivação para o estudo. Além disso, recursos tecnológicos podem tornar as aulas mais dinâmicas, aumentando a autonomia de estudo e dando uma nova perspectiva para a abordagem dos conteúdos desenvolvidos na sala de aula do Ensino Médio.

\section{Prova De Matemática E Suas Tecnologias}

Segundo Costa e Santos (2013), o Brasil ocupa a 84 colocação em um ranking com 187 países no Índice de Desenvolvimento Humano da Organização (IDH) das Nações Unidas e, na educação, ocupa as últimas posições nas comparações internacionais, e os resultados das avaliações nacionais confirmam tais resultados. Para os autores a universalização do Ensino Médio não resolveu a questão da qualidade de ensino e aprendizagem na Educação Básica no país.

Segundo o NCTM (2015), para uma aprendizagem significativa da matemática, as ferramentas e tecnologias devem ser consideradas características indispensáveis para a sala de aula, fazendo parte das tecnologias uma ampla variedade de dispositivos portáteis, tablets, computadores portáteis e de mesa, que podem ser utilizados para ajudar os estudantes a dar sentido aos conteúdos matemáticos, auxiliando no desenvolvimento do raciocínio matemático e na comunicação utilizando matemática.

O Enem é um "exame diferente dos exames tradicionais" (Murrie, 2006, p.7), a prova de Matemática e Suas Tecnologias apresenta conceitos de situações-problema interdisciplinares e contextualizados.

Verifica-se um exemplo de questão contextualizada, colocado na prova de 2017 , onde o aluno deveria aplicar conhecimentos de Geometria para calcular a altura mínima de um viaduto localizado no município de Porto Alegre/RS. Seguidamente caminhões ficam presos nesse viaduto e o Enem utilizou esse fato para maximizar ao aluno a importância da Geometria na construção de um viaduto (Figura 1). 
A manchete demonstra que o transporte de grandes cargas representa cada vez mais preocupação quando feito em vias urbanas.

\section{Caminhão entala em viaduto no Centro}

Um caminhão de grande porte entalou embaixo do viaduto no cruzamento das avenidas Borges de Medeiros e Loureiro da Silva no sentido Centro-Bairro, próximo à Ponte de Pedra, na capital. Esse veículo vinha de São Paulo para Porto Alegre e transportava três grandes tubos, conforme ilustrado na foto.

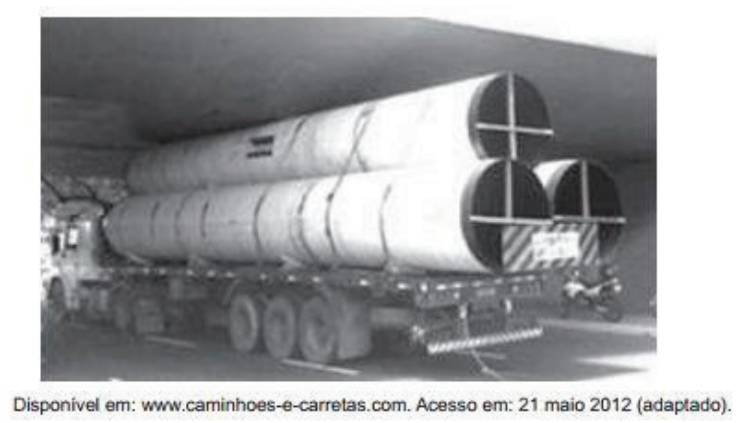

Cosidere que o raio externo de cada cano da imagem seja 0,60 m e que eles estejam em cima de uma carroceria cuja parte superior está a $1,30 \mathrm{~m}$ do solo. $\mathrm{O}$ desenho representa a vista traseira do empilhamento de canos.

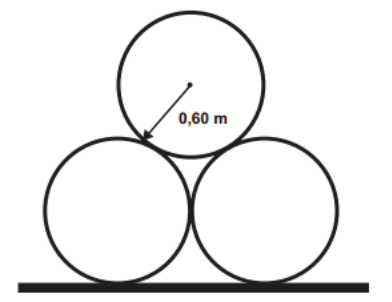

A margem de segurança recomendada para que um veículo passe sob um viaduto é que a altura total do veículo com a carga seja, no mínimo, 0,50 $\mathrm{m}$ menor do que a altura do viaduto.

Considere 1,7 como aproximação para $\sqrt{3}$.

Qual deveria ser a altura mínima do viaduto, em metro, para que esse caminhão pudesse passar com segurança sob seu vão?
A) 2,82
B) 3,52
C) 3,70
D) 4,02
E) 4,20

Figura 1: Questão 153 da prova de Matemática e suas Tecnologias Fonte: Exame Nacional do Ensino Médio, INEP, 2017.

A prova de Matemática é composta por quarenta e cinco questões objetivas de múltipla escolha, nas quais abordam os conteúdos de Matemática do Ensino Básico. A pontuação máxima e mínima da prova muda de ano para ano, sendo utilizada a Teoria de Resposta ao Item (TRI), como metodologia de correção utilizada no exame. Os conteúdos do Ensino Básico são exigidos dentro de sete competências e trinta habilidades.

Apresenta-se, na Figura 2, as competências da Matriz de Referência 2017 abordadas na prova. 


\begin{tabular}{|c|l|}
\hline Áreas & \multicolumn{1}{c|}{ Competências } \\
\hline 1 & Construir significados para os números naturais, inteiros, racionais e reais. \\
\hline 2 & $\begin{array}{l}\text { Utilizar o conhecimento geométrico para realizar a leitura e a representação da } \\
\text { realidade e agir sobre ela. }\end{array}$ \\
\hline 3 & $\begin{array}{l}\text { Construir noções de grandezas e medidas para a compreensão da realidade e a } \\
\text { solução de problemas do cotidiano. }\end{array}$ \\
\hline 4 & $\begin{array}{l}\text { Construir noções de variação de grandezas para a compreensão da realidade e } \\
\text { a solução de problemas do cotidiano. }\end{array}$ \\
\hline 5 & $\begin{array}{l}\text { Modelar e resolver problemas que envolvem variáveis socioeconômicas ou } \\
\text { técnico-científicas, usando representações algébricas. }\end{array}$ \\
\hline 6 & $\begin{array}{l}\text { Interpretar informações de natureza científica e social obtidas da leitura de } \\
\text { gráficos e tabelas, realizando previsão de tendência, extrapolação, interpolação } \\
\text { e interpretação. }\end{array}$ \\
\hline 7 & $\begin{array}{l}\text { Compreender o caráter aleatório e não-determinístico dos fenômenos naturais e } \\
\text { sociais e utilizar instrumentos adequados para medidas, determinação de } \\
\text { amostras e cálculos de probabilidade para interpretar informações de variáveis } \\
\text { apresentadas em uma distribuição estatística. }\end{array}$ \\
\hline
\end{tabular}

Figura 2: Competências da Matriz de Referência do Enem 2017

Fonte: Matriz de Referência de Matemática e suas Tecnologias, BRASIL, 2017.

Observa-se na tabela os conteúdos mais abordados na prova de Matemática e suas Tecnologias do Enem 2016, de acordo com as competências e habilidades.

Tabela 1: Conteúdos, competências e Número de questões do Enem 2016.

\begin{tabular}{l|c|c}
\multicolumn{1}{c|}{ Conteúdos } & Competências & Número de questões \\
\hline Geometria Plana e Espacial & 2 & 9 \\
Porcentagem & 1 & 8 \\
Regra de Três & 4 & 6 \\
Interpretação de gráficos ou tabelas para resolução de problemas & 6 & 7 \\
ou fazer inferências. & 7 & 6 \\
Estatística & 4 & 4 \\
Variação de grandezas & 1 & 6 \\
Raciocínio Lógico e Matemática do Ensino Fundamental & 1 & 2 \\
Análise Combinatória & 5 & 2 \\
Funções & 7 & 1 \\
Probabilidade & 5 & 2 \\
Logaritmo & & 1 \\
Progressão Aritmética & 1 & 2 \\
Razão & 4 & 1 \\
Escala e Conversão de Unidades & 3 & \\
\hline
\end{tabular}

Fonte: A pesquisa.

Os conteúdos abordados na prova de Matemática e suas Tecnologias do Enem 2017, de acordo com as competências e habilidades, estão apresentados na Tabela 2. 
Tabela 2: Conteúdos, competências e Número de questões do Enem 2017.

\begin{tabular}{l|c|c}
\multicolumn{1}{c|}{ Conteúdos } & Competências & Número de questões \\
\hline Geometria Plana e Espacial & 2 & 10 \\
Porcentagem & 1 & 6 \\
Regra de Três & 4 & 4 \\
Interpretação de gráficos ou tabelas para resolução de problemas & 6 & 7 \\
ou fazer inferências. & 7 & 3 \\
Estatística & 4 & 1 \\
Variação de grandezas, diretas ou inversamente. & 1 \\
Raciocínio Lógico e Matemática do Ensino Fundamental & 1 & 14 \\
Análise Combinatória & 5 & 4 \\
Funções & 7 & 7 \\
Probabilidade & 5 & 3 \\
Logaritmo & 1 & 1 \\
Progressão Aritmética & 4 & 1 \\
Razão & 3 & 2 \\
Escala e Conversão de Unidades & 1 & 1 \\
Matemática Financeira & 1 \\
\hline
\end{tabular}

Fonte: A pesquisa.

No ano de 2016, as competências 1 e 4 foram as mais exigidas na prova. A competência 1 foi cobrada em 17 questões nos conteúdos de Porcentagem, Raciocínio Lógico e Matemática do Ensino Fundamental, Análise Combinatória e Progressão Aritmética. A competência 4 foi exigida em 12 questões da prova nos conteúdos de Regra de Três, Variação de grandezas e Razão.

Em 2017, as competências mais contempladas foram 1 e 2. A competência 1 apareceu em 26 questões da prova nos conteúdos de Porcentagem, Raciocínio Lógico, Análise Combinatória e Progressão Aritmética. E a competência 2, foi exigida em 10 questões da prova nos conteúdos de Geometria Plana e Espacial.

Os conteúdos mais exigidos na prova de Matemática e suas Tecnologias no ano de 2016, foram: Geometria Plana e Espacial, Porcentagem, Interpretação de gráficos ou tabelas para resolução de problemas ou fazer inferências, Regra de três, Raciocínio Lógico e Matemática do Ensino Fundamental.

Em 2017, os conteúdos mais exigidos em 2016 apareceram novamente entre os mais abordados, acrescentado do conteúdo de funções que passou de duas para sete questões, entrando para os conteúdos mais abordados da prova neste ano.

É importante frisar que conteúdos do Ensino Médio como Matrizes, Progressão Geométrica e Números Complexos, não foram abordados pela prova. Uma questão da prova de Análise Combinatória abordou uma questão de Combinação por Repetição, gerou críticas, pois alguns professores consideram que esse conteúdo não é visto no Ensino Médio.

Apresenta-se, na Figura 3, a questão de Análise Combinatória da prova de 2017. 
Um brinquedo infantil caminhão-cegonha é formado por uma carreta e dez carrinhos nela transportados, conforme a figura.

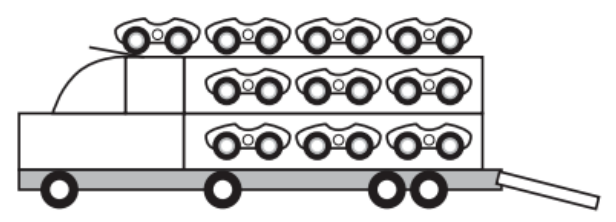

No setor de produção da empresa que fabrica esse brinquedo, é feita a pintura de todos os carrinhos para que o aspecto do brinquedo fique mais atraente. São utilizadas as cores amarelo, branco, laranja e verde, e cada carrinho é pintado apenas com uma cor. O caminhão-cegonha deve haver pelo menos um carrinho de cada uma das quatro cores disponíveis. Mudança de posição dos carrinhos no caminhão-cegonha não gera um novo modelo do brinquedo.

Com base nessas informações, quantos são os modelos distintos do brinquedo caminhão-cegonha que essa empresa pode produzir?
A) $C_{6,4}$
B) $C_{9,3}$
C) $C_{10,4}$
D) $6^{4}$
E) $4^{6}$

Figura 3: Questão 143, caderno azul, Enem 2017

Fonte: Exame Nacional do Ensino Médio, INEP, 2017.

Para resolver essa questão foram exigidos conhecimentos de Análise Combinatória, compreendidos na competência de área 1 do Enem.

O enunciado da questão indica que a mudança de posição dos carrinhos no caminhãocegonha não gera um novo modelo, isto significa que se trata de uma combinação. Ao interpretar a questão, observa-se que em cada caminhão-cegonha deve ter pelo menos um carrinho de cada uma das quatro cores: amarelo, branco, laranja, verde. Nos demais carrinhos, as cores podem ser repetidas, isto gera uma combinação com repetição.

$$
\begin{gathered}
\text { Combinação por repetição }=\text { Combinação } o_{n+p-1, p} \\
n=4 \text { (cores distintas) } \\
p=6 \text { (posições em que os carrinhos com cores repetidas serão colocadas) } \\
C_{4+6-1,6}=C_{9,6}
\end{gathered}
$$

Utilizando a Combinação Complementar:

$$
C_{9,6}=C_{9,3} \text {. }
$$

Logo, a resposta da questão é alternativa b.

\section{Uso Das Tecnologias Da Informação E Comunicação Para Desenvolver As Questões Propostas Do Enem}

As TIC correspondem as tecnologias que interferem e medeiam os processos informacionais e comunicativos dos seres humanos (OLIVEIRA et. al, 2015). Essas tecnologias 
fazem parte do cotidiano do aluno. A utilização das TIC no ambiente escolar pode servir como uma ligação entre a mesma e o ambiente do aluno.

A busca pela incorporação das tecnologias no Ensino Básico tem sido uma das metas do MEC. No ano de 2016, mais de 24 milhões de estudantes de escolas públicas brasileiras tiveram acesso a tecnologias. No entanto cabe ressaltar que, "não basta dar a estrutura, é necessário capacitar o corpo docente e oferecer conteúdos a serem trabalhados em sala de aula" (ALMEIDA, 2016).

Dessa maneira, esse artigo investigou como os professores podem incorporar os recursos tecnológicos no planejamento didático para a resolução das questões e conteúdos exigidos na prova de Matemática e Suas Tecnologias do Enem.

A seguir, apresentam-se dois exemplos da utilização do software GeoGebra na resolução de questões das provas de 2016 e 2017.

Na Questão 136 (Figura 4), do caderno azul, do Enem de 2016, sugere-se o uso do software GeoGebra para resolução da questão, com o objetivo de preparar os estudantes para resolverem atividades semelhantes a essa.

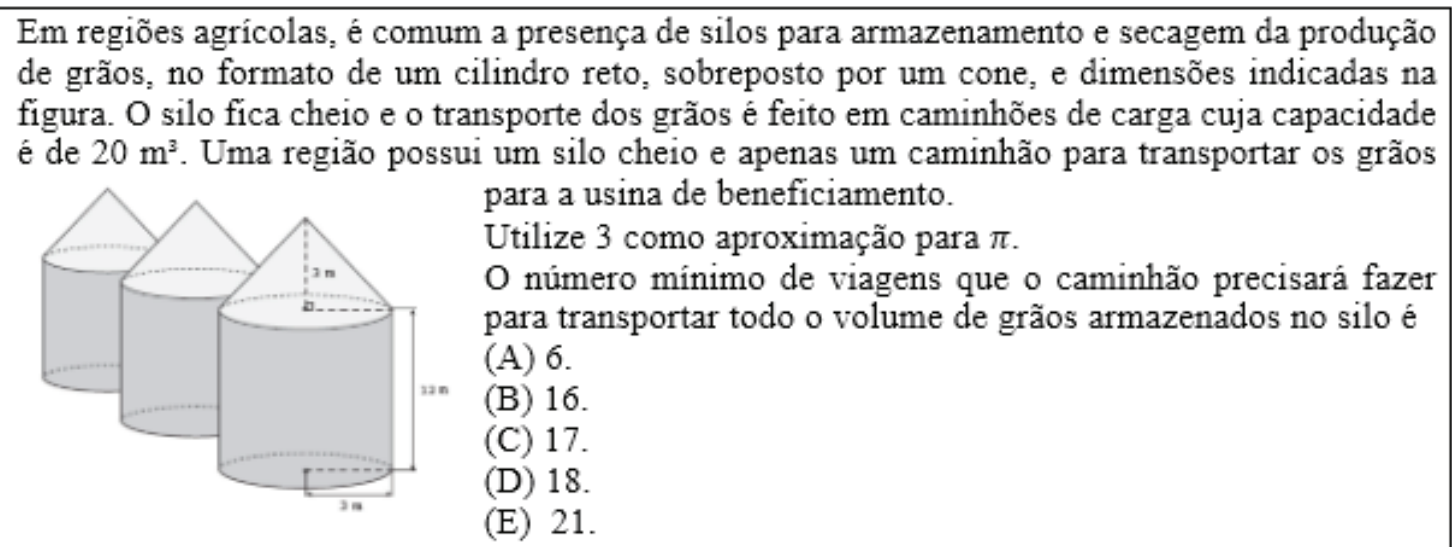

Figura 4: Questão 136 do Enem de 2016

Fonte: Exame Nacional do Ensino Médio, INEP, 2016.

Para resolver esta questão são exigidos conhecimentos de Geometria Espacial, compreendidos na competência de área 2, na qual exige o reconhecimento das características de figuras espaciais, onde conhecimentos geométricos devem ser aplicados para resolução de problemas envolvendo possíveis situações decorrentes do cotidiano.

$\mathrm{O}$ enunciado indica que o silo tem formato de um cilindro reto, sobreposto por um cone. Em seguida, revela que a capacidade máxima que um caminhão suporta carregar é $20 \mathrm{~m}^{3}$. Para calcular o número mínimo de viagens que o caminhão terá que fazer para transportar o volume do silo é necessário, em um primeiro momento, calcular o volume do silo. 
O volume do silo é o volume do cilindro mais o volume do cone.

Recomenda-se utilizar o software GeoGebra para visualização do volume total do silo, pois este software possui um recurso para visualização de figuras em $3 \mathrm{D}$, onde pode ser inserida a figura que representa o volume do cilindro e volume do cone que resultarão no volume do silo.

A seguir indica-se as instruções para realizar a atividade.

Como primeiro passo, indica-se abrir o GeoGebra e selecionar o menu exibir.

Uma janela com opções irá aparecer, conforme apresenta-se na Figura 5.

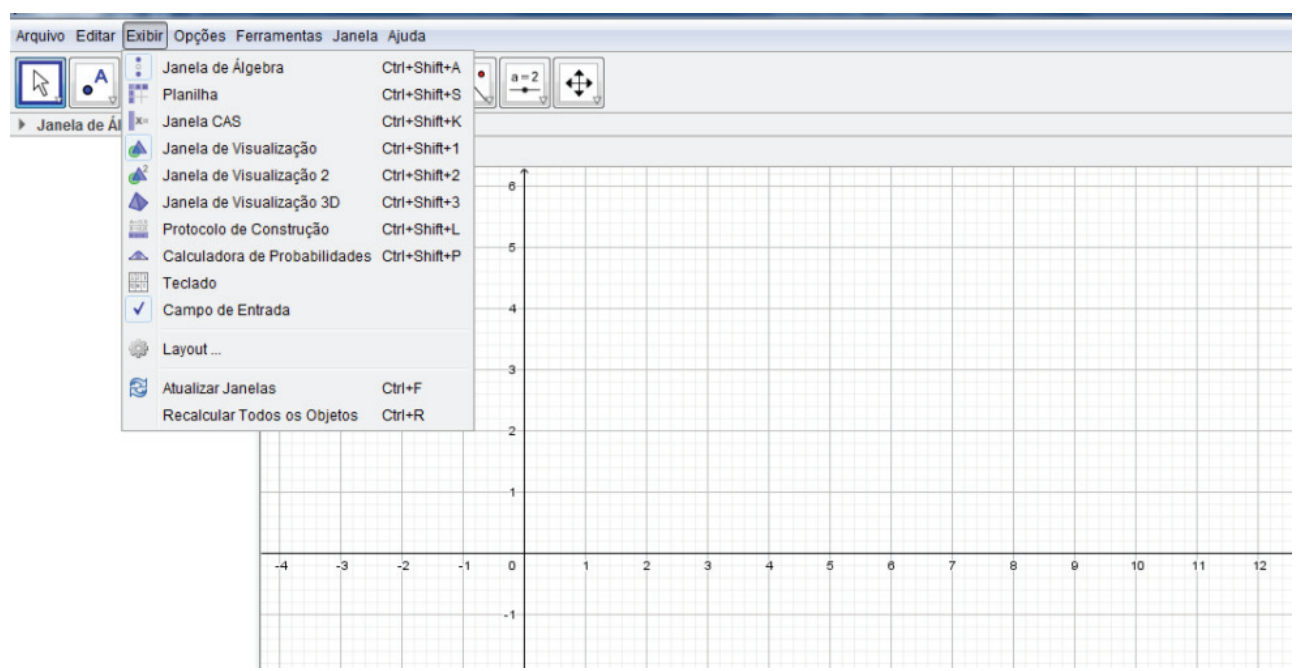

Figura 5: Menu Exibir do Software GeoGebra Fonte: A pesquisa.

Nessa janela, selecionar a opção, Janela de Visualização 3D . Essa opção também poderá ser selecionada pelo comando $\mathrm{Ctrl}+\mathrm{Shift+3}$

Uma nova janela contendo três eixos surgirá no lado direito da janela inicial do GeoGebra, conforme Figura 6.

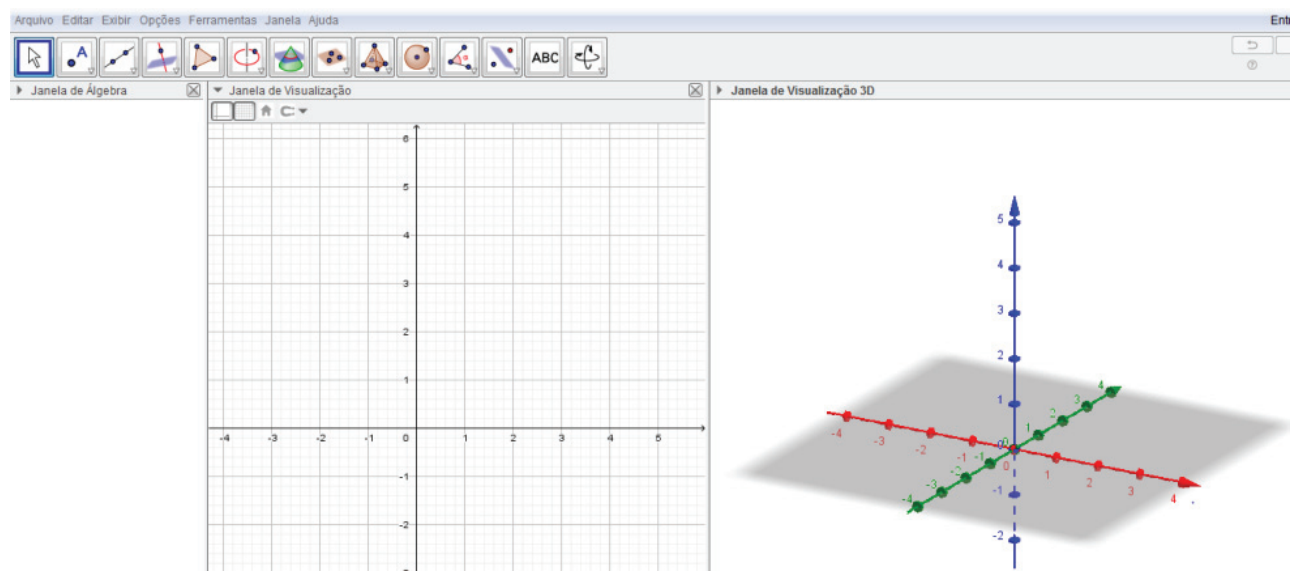

Figura 6: Janelas de visualização 2D e 3D

Fonte: A pesquisa. 
Para denominar os rótulos de cada eixo e as unidades nas quais trabalhar, clica-se com o botão direito do mouse em qualquer lugar da janela e aparecerá um novo menu (Figura 7).

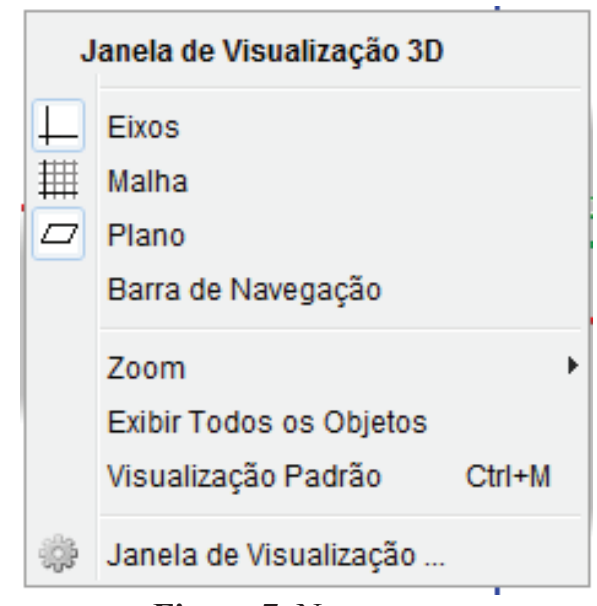

Figura 7: Novo menu

Fonte: A pesquisa.

Neste menu, selecionar a opção janela de visualização. Marcar a opção Exibir Eixo X e rótulo " $x$ ". De modo semelhante, deve ser feito para o eixo Y e para o eixo $Z$, conforme apresenta-se na Figura 8.

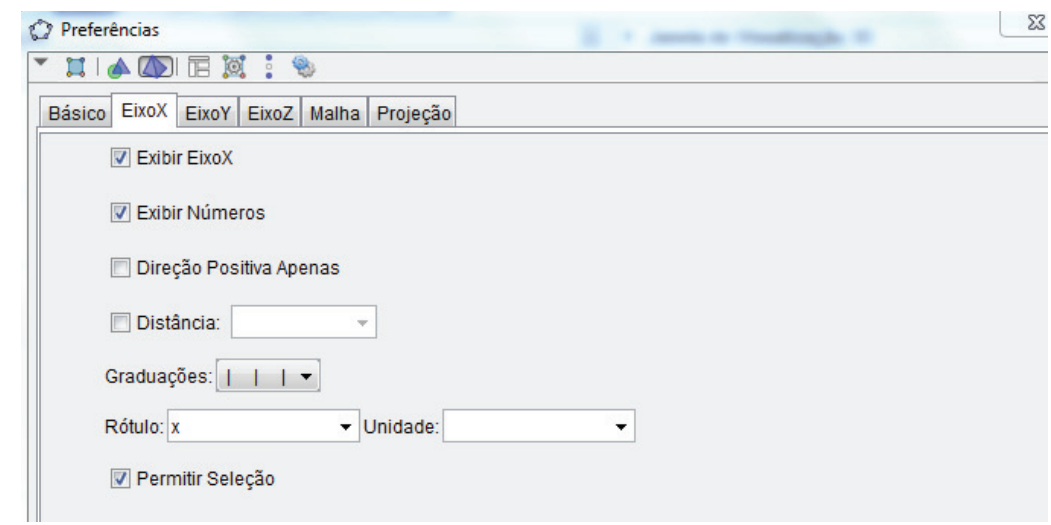

Figura 8: Exibir Eixo $X$ e rótulo " $X$ "

Fonte: A pesquisa.

A opção "unidades" também deverá ser definida, a unidade das dimensões do silo, no problema, é metros, logo deve-se marcar a unidade metros.

Após rotular os eixos e inserir as unidades, inicia-se a construção da figura geométrica do silo (cilindro reto, sobreposto por um cone).

Inicialmente, clicar na janela de visualização 2D e selecionar a opção

\section{Círculo dados Centro e Raio}

Clicar no ponto $(0,0)$, e após estipular o valor 3 para o raio. Um círculo de raio 3 aparecerá nas janelas de visualização (Figura 9). 


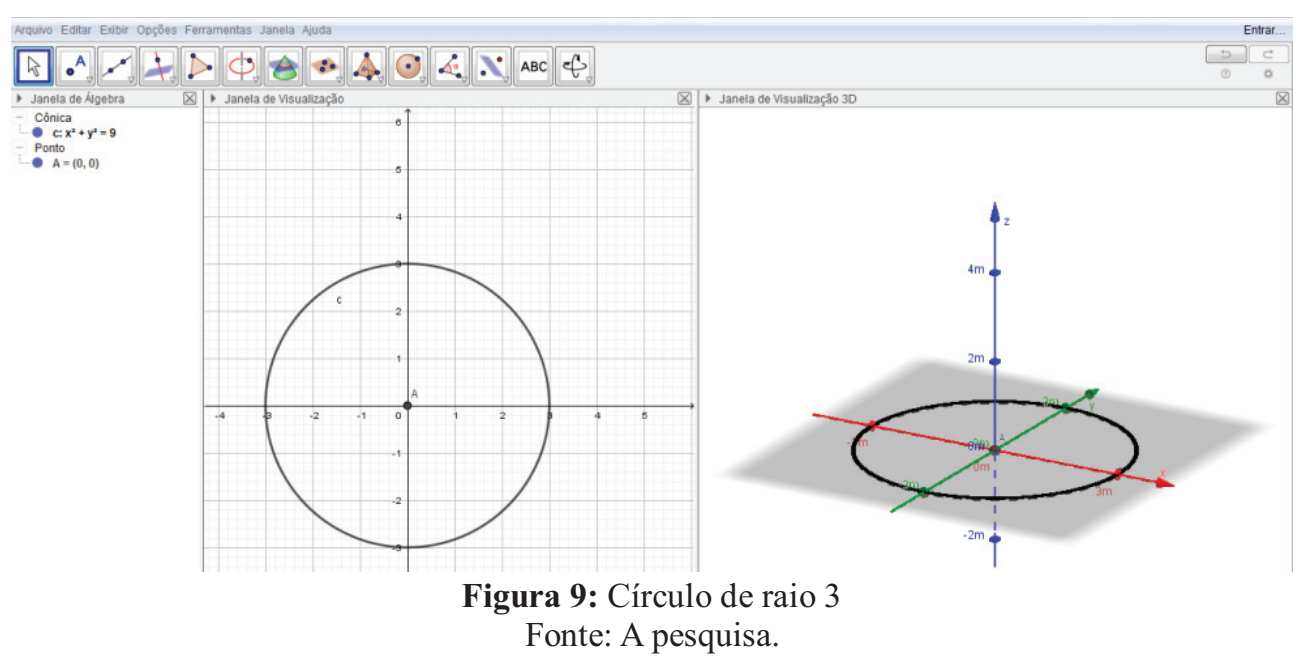

A seguir clicar na janela 3D e selecionar a opção

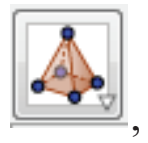

Extrusão para Prisma ou Cilindro

clicar no círculo da janela de visualização 3D.

Aparecerá uma janela solicitando a altura, devendo ser indicado 12 para a altura do silo, conforme os dados do problema (Figura 10). Esta construção está apresentada na Figura 10.

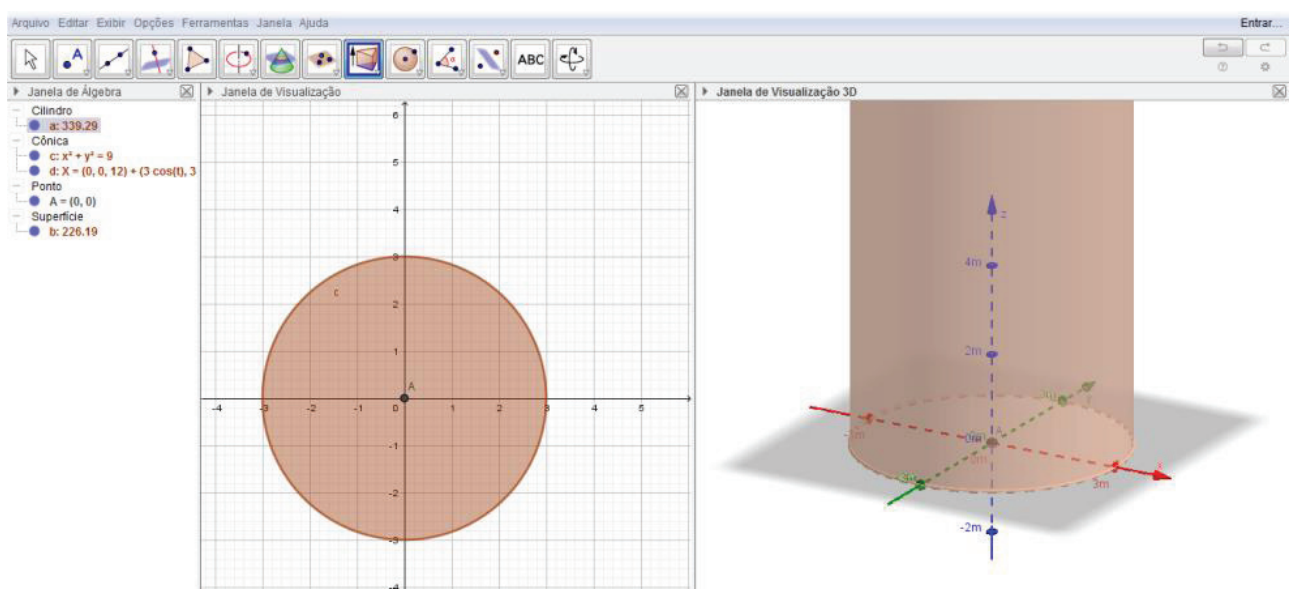

Figura 10: Cilindro construído

Fonte: A pesquisa.

Uma dificuldade que se apresenta ao realizar esta construção, é visualizar o cilindro de forma que a altura fique exposta. Para tanto, aconselha-se clicar na tela de visualização 3D e pressionar simultanemanete as teclas $\mathrm{Ctrl}$ e - (Ctrl+-), até atingir uma visualização completa do cilindro, conforme apresenta-se na Figura 11. 


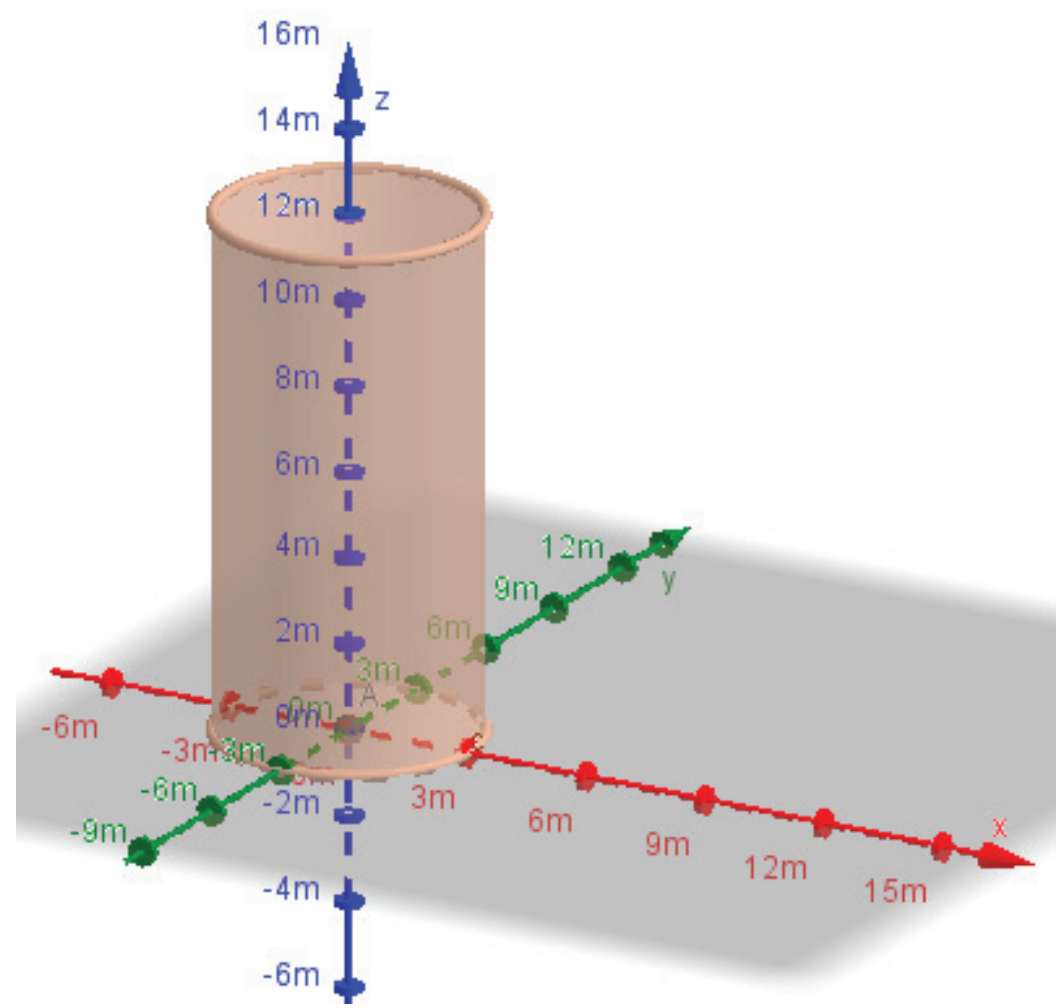

Figura 11: Visualização completa do cilindro.

Fonte: A pesquisa.

Para visualizar o volume do cone, no software GeoGebra, procede-se de forma semelhante. Inicialmente, clicar na janela de visualização $2 \mathrm{D}$ e selecionar a opção

\section{(D) Círculo dados Centro e Raio}

Clicar no ponto $(0,0)$, após estipular o valor 3 para o raio. Um círculo de raio 3 aparecerá nas janelas de visualização, conforme Figura 12.

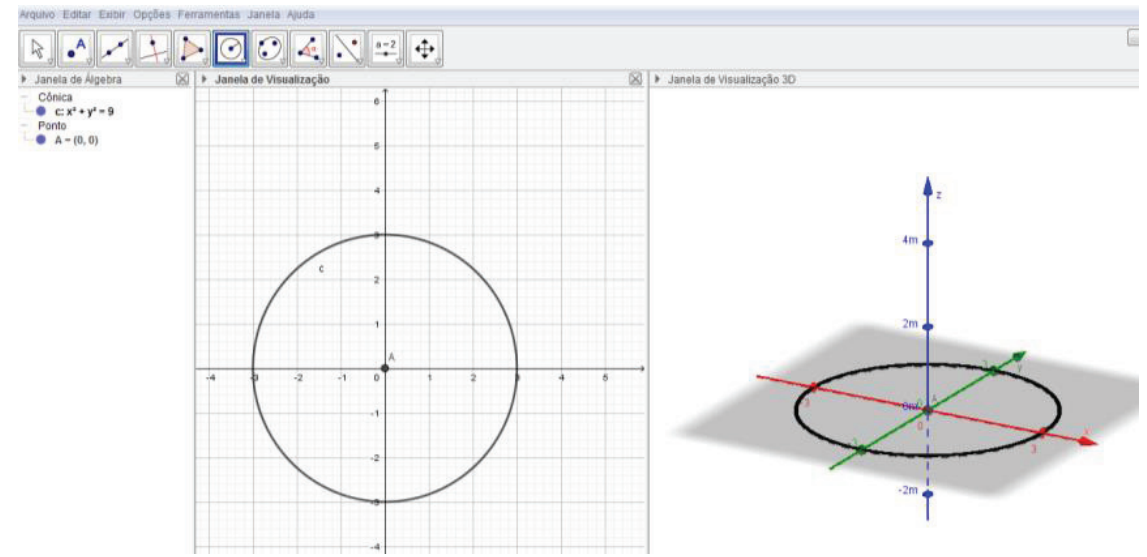

Figura 12: Círculo de raio 3

Fonte: A pesquisa.

Clicar na janela 3D e selecionar a opção

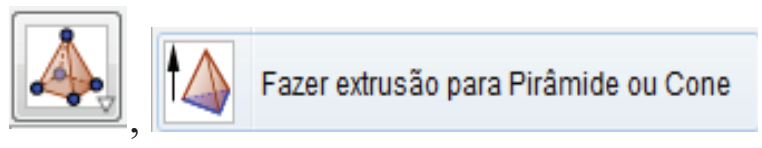


A seguir, clicar no círculo da janela de visualização 3D. Abrirá uma janela solicitando a altura. Inserir 3 para a altura, conforme na figura 13.

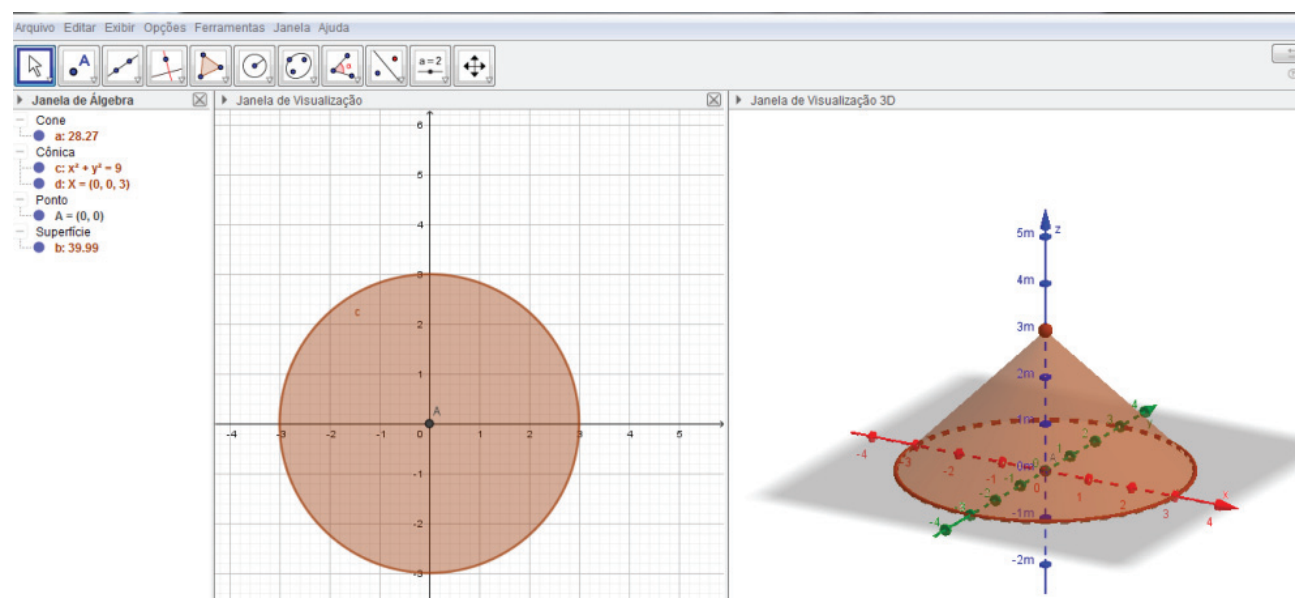

Figura 13: Altura 3.

Fonte: A pesquisa.

Após a construção dos sólidos, deve-se calcular os seus volumes. Para tanto deveselecionar, em cada construção, o sólido desejado (cilindro e cone), na ferramenta volume ivg Volume do menu cima da figura construída, conforme Figura 14.

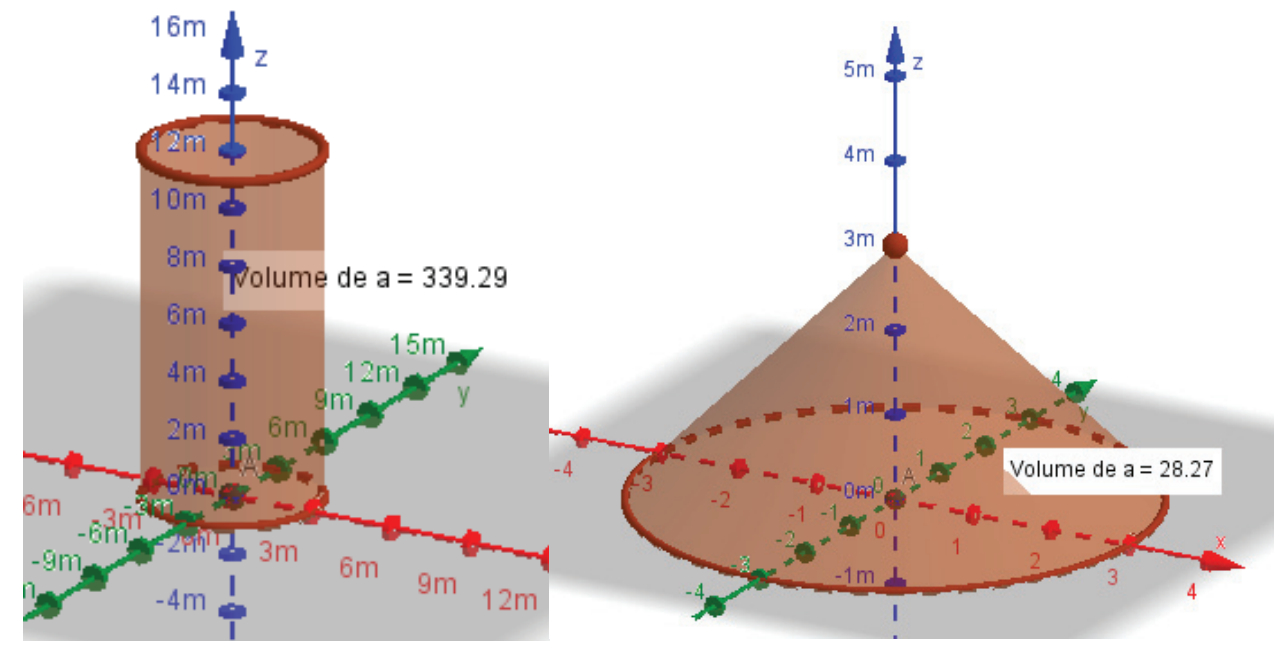

Figura 14: Volume dos sólidos Fonte: A pesquisa.

Porém, a questão solicita que seja utilizado $\pi=3$ e, o software utilizado o valor real de $\pi$. Desta forma, apresenta-se o cálculo do volume deste silo utilizando as fórmulas já conhecidas.

Como o silo é composto de um cilindro reto e de um cone, seu volume é encontrado pela soma dos volumes destes dois sólidos. 
O volume do cilindro é dado por:

$$
V_{\text {cilindro }}=\text { Área da base } \cdot \text { altura. }
$$

Sugere-se uma visualização da área da base e altura, conforme figura 15 .
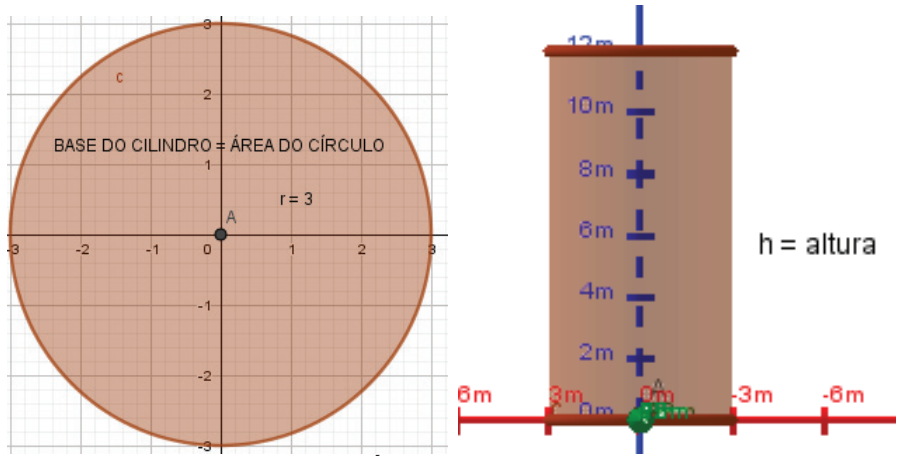

Figura 15: Área e altura do cilindro Fonte: A pesquisa.

$$
\text { Área do círculo }=\pi r^{2} \text {. }
$$$$
\pi \cong 3 \text {. }
$$$$
r=3 m \text {. }
$$

$$
\text { altura }=12 \text {. }
$$

Área da base $\cdot$ altura $=3 \pi \cdot(3 m)^{2} \cdot 12 m=324 m^{3}$.

Portanto o volume do cilindro é $324 \mathrm{~m}^{3}$.

O volume do cone é dado por:

$$
V_{\text {cone }}=\frac{\text { área da base } \cdot \text { altura }}{3}=\frac{\pi \cdot r^{2} \cdot h}{3} .
$$

Sugere-se uma demonstração da área da base e altura, conforme figura 16.
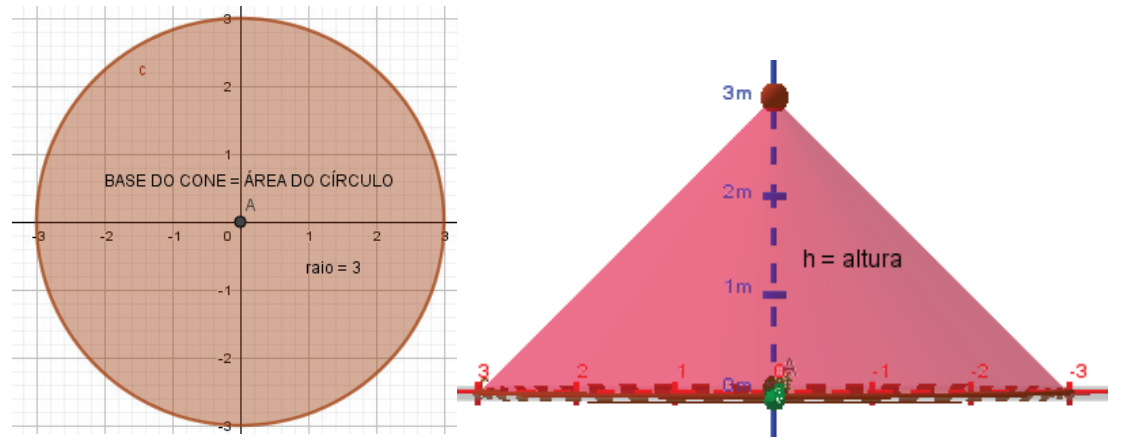

Figura 16: Área da base e altura do cone. Fonte: A pesquisa.

$$
\begin{gathered}
V_{\text {cone }}=\frac{3 \cdot(3 m)^{2} \cdot 3 m}{3}=27 \mathrm{~m}^{3} . \\
V_{\text {silo }}=324 \mathrm{~m}^{3}+27 \mathrm{~m}^{3}=351 \mathrm{~m}^{3} .
\end{gathered}
$$

Portanto, o volume total em grãos armazenados no silo é igual a $351 \mathrm{~m}^{3}$. Como o caminhão suporta no máximo $20 \mathrm{~m}^{3}$, devemos encontrar a razão entre o volume total e a 
capacidade máxima que o caminhão suporta, que indicará quantas viagens o caminhão levará para transportar todo o volume de grãos contido no silo: $\frac{351 \mathrm{~m}^{3}}{20 \mathrm{~m}^{3}}=17,55$. Logo, serão necessárias 18 viagens (Alternativa $\mathrm{D})$.

No segundo exemplo apresenta-se a questão 168 (Figura 17), do caderno azul, do Enem de 2017, sugerindo o uso do software GeoGebra para resolução da questão.

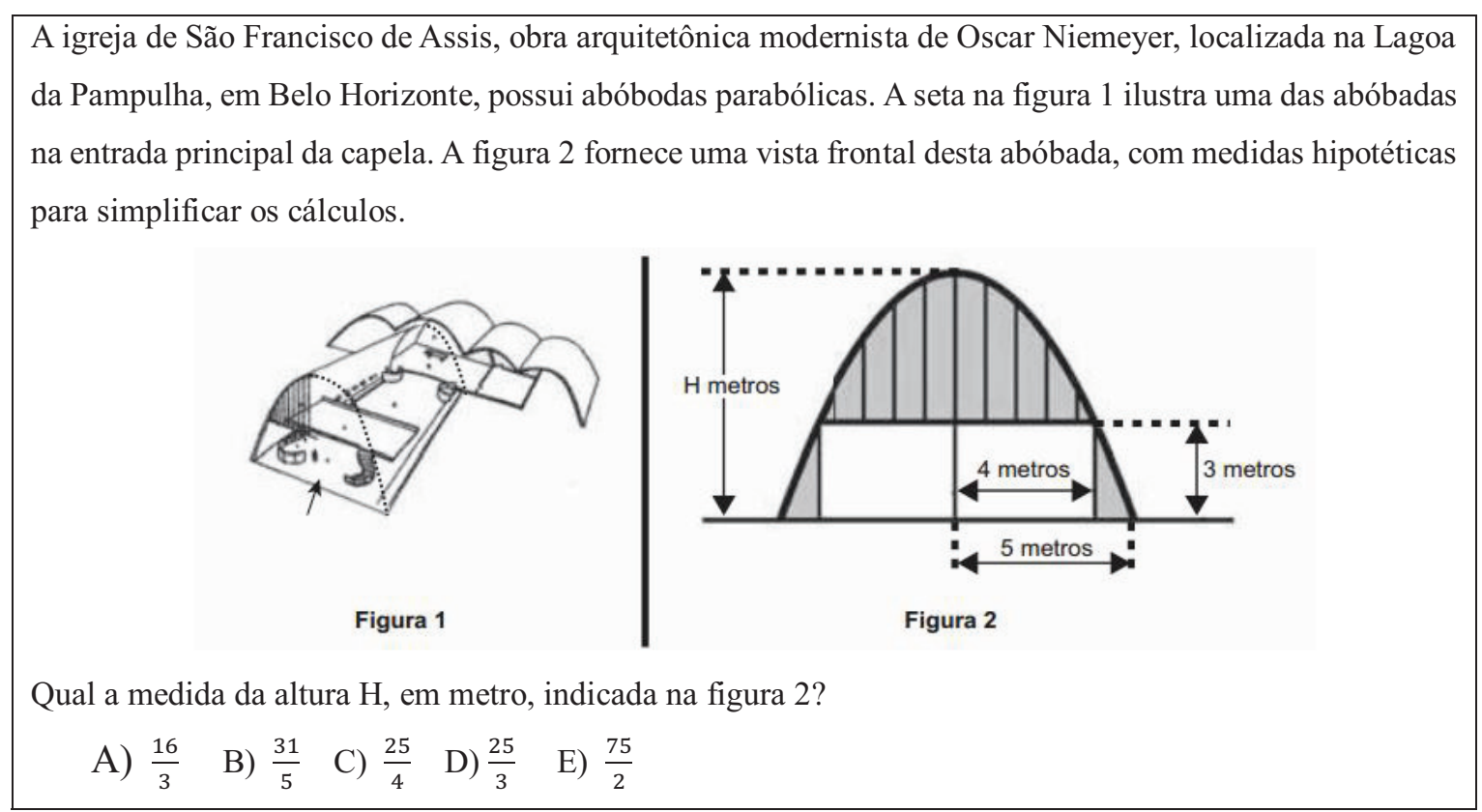

Figura 17: Questão 136 do Enem de 2017.

Fonte: Exame Nacional do Ensino Médio, caderno azul, 2017.

Para resolver essa questão são exigidos conhecimentos de funções, compreendidos na competência de área 5 do Enem.

O enunciado da questão indica que a igreja de São Francisco de Assis, possui uma abóbada parabólica na sua entrada principal. A visualização frontal dessa abóboda está representada pela parábola encontrada na Figura 2. Observando essa forma, nota-se que se trata de uma parábola com a concavidade voltada para baixo e que sua altura, exigida na questão, é o ponto máximo dessa parábola. Como sugestão para facilitar a resolução dessa questão, devese esboçar essa parábola em um plano cartesiano. Dessa maneira, o eixo $y$ ficará sobre o eixo da altura e o $x$, representará o solo da abóboda parabólica. Utilizou-se o software GeoGebra para o esboço da mesma em um plano cartesiano.

A seguir indica-se as instruções para realizar o esboço dessa parábola no plano cartesiano:

Como primeiro passo, deve-se nomear os eixos. Para isso, na tela inicial do GeoGebra, clicar com o botão direito na tela de exibição. Uma janela de visualização, aparecerá com a opção janela de visualização (Figura 18). 


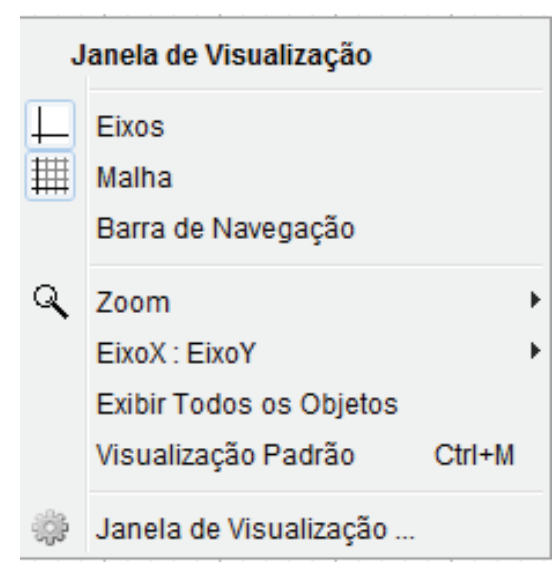

Figura 18: Janela de Visualização Fonte: A pesquisa.

Ao clicar na opção, Janela de Visualização, uma nova janela, chamada de preferências, exibida na Figura 19, surgirá.

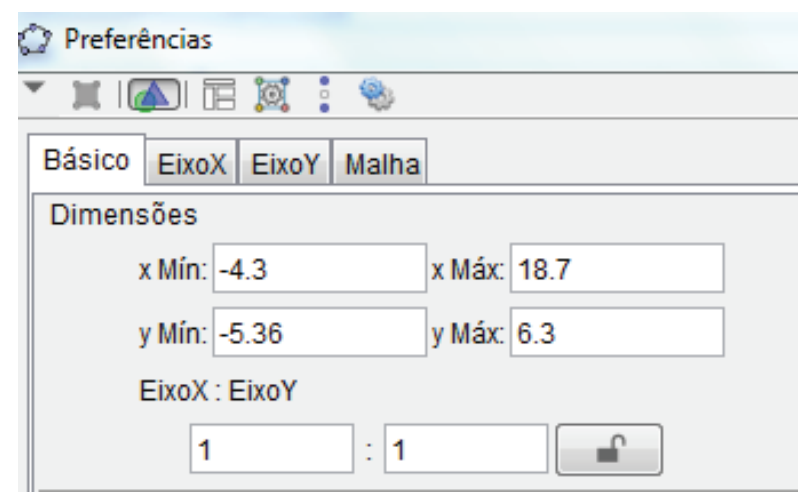

Figura 19: Janela de Preferências Fonte: A pesquisa.

Na janela de preferências, escolher a opção EixoX. Na opção rótulo, selecione "x", para esse eixo. Na opção EixoY, selecione "y".

Como segundo passo aconselha-se esboçar a abóbada parabólica.

Pela figura 2, dada na questão, observa-se que a parábola possui a concavidade voltada para baixo e intersecciona o eixo das abscissas (solo), nos pontos $(-5,0)$ e $(5,0)$. A questão não informa a lei de formação, no entanto, o software GeoGebra, possui um recurso chamado de controle deslizante, com o qual será possível descobri-la.

Para habilitar esse controle deslizante, inserir na caixa de entrada do GeoGebra, Entrada: Deslizantes, escolher a opção, Criar Controles Deslizantes.

Nesse instante, aparecerão no GeoGebra, a função na Janela de Álgebra (Figura 20), o 
controle deslizante (Figura 21) e o esboço da parábola $-x^{2}+1$ (Figura 22).

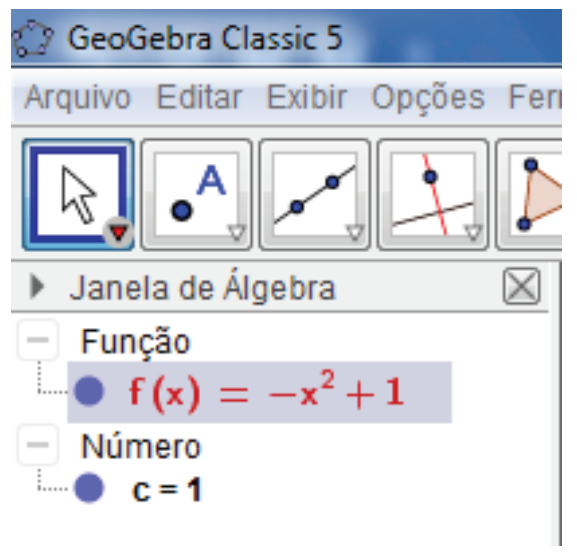

Figura 20: Função

Fonte: A pesquisa.

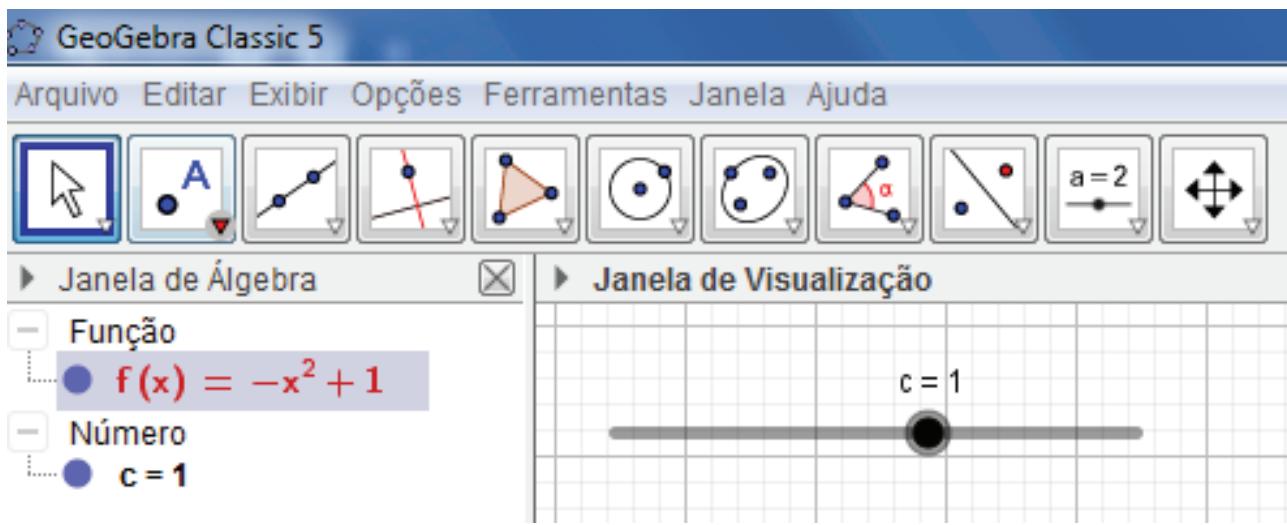

Figura 21: Controle deslizante Fonte: A pesquisa.

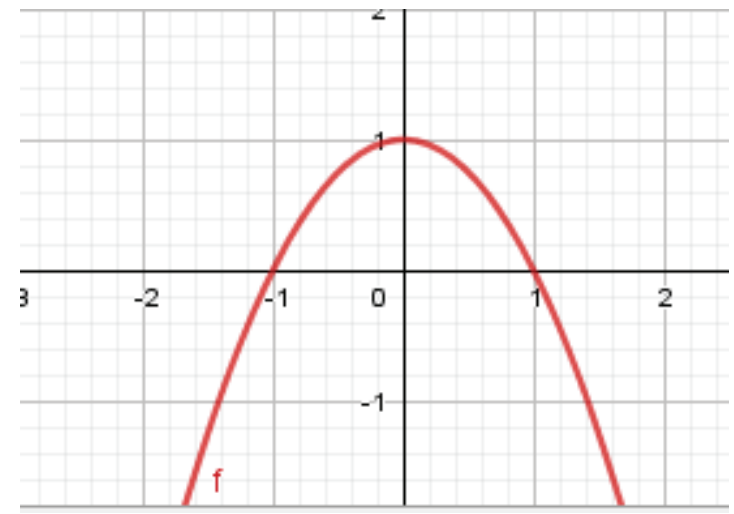

Figura 22: Esboço da parábola Fonte: A pesquisa.

O controle deslizante está definido pelo GeoGebra no intervalo de -5 a 5 . Clicar com o botão direito no controle deslizante e selecionar a opção Propriedades ... . Para alterar esse intervalo inserir $\min :-25 \quad \max 25$. Alterar o controle deslizante para direita 
até chegar em 25.

Observe na Figura 23 que os vértices da parábola interseccionaram o eixo das abscissas em $(-5,0)$ e $(5,0)$.

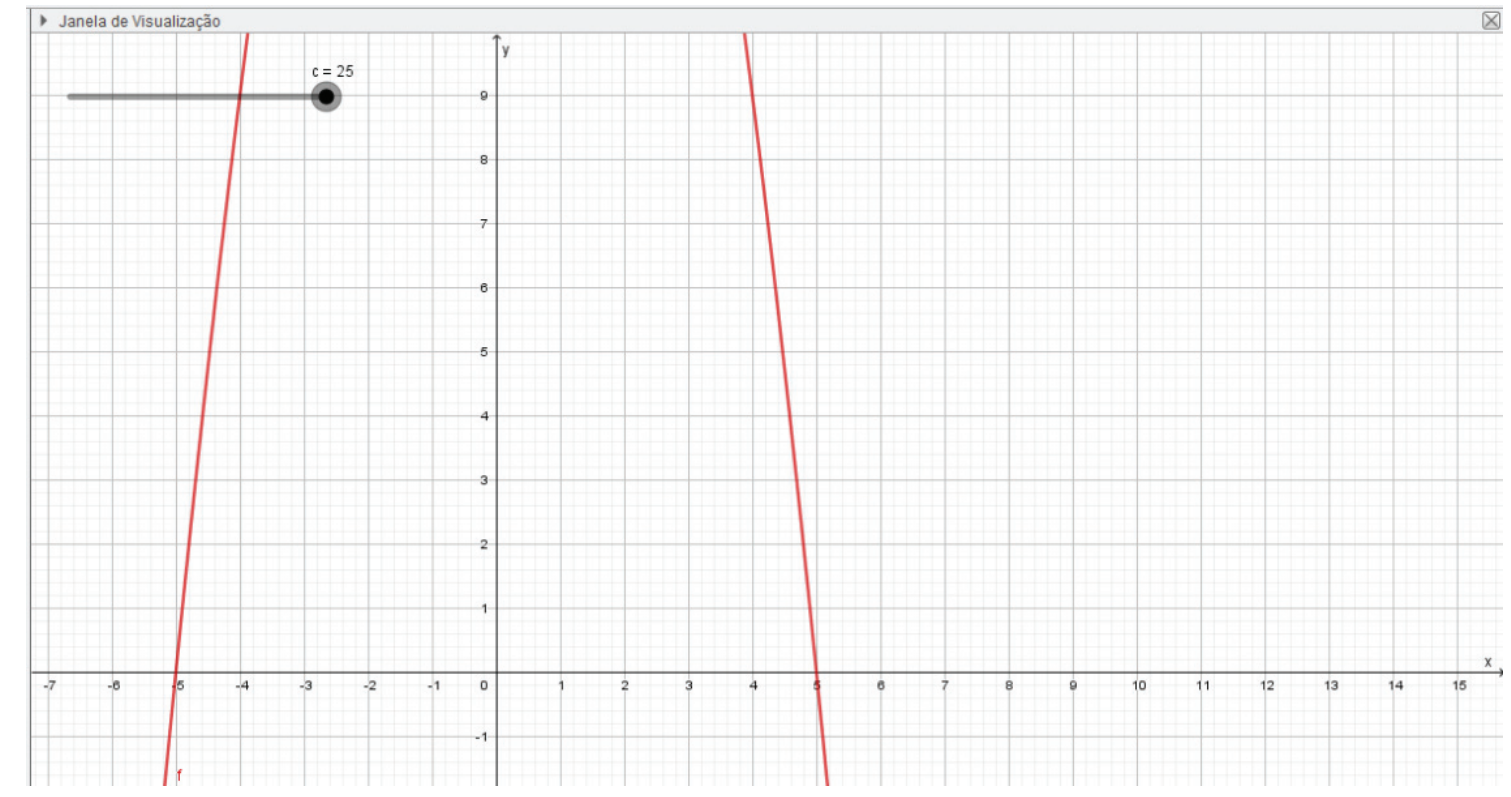

Figura 23: Intersecção nos pontos $(-5,0)$ e $(5,0)$.

Fonte: A pesquisa.

Para melhor visualização dessa parábola, sugere-se clicar com o botão "Ctrl” na Janela de Visualização do GeoGebra e pressionar menos até a imagem da parábola aparecer completamente. Além disso, estipular a distância para as unidades do EixoX e EixoY, clicando com o botão direito na Janela de Visualização e entrando na opção distância e inserir 1, V Distância: $1 \quad-$ O esboço da parábola representada na Figura 2 da questão está construída na Figura 24.

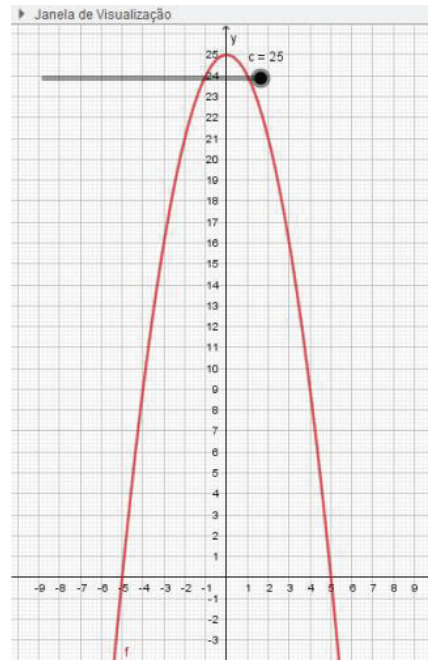

Figura 24: Parábola construída Fonte: A pesquisa. 
Após o primeiro e o segundo passo, o software GeoGebra demonstrará em sua Janela de Álgebra, a lei de formação de uma das parábolas que passam pelos pontos $(-5,0)$ e $(5,0)$, - Função

$f(x)=-x^{2}+25$. Para verificar se essa lei de formação é a correta, substituir na lei de formação o ponto dado na Figura 2 da questão, quando o $x$ assume o valor de 4, então y é 3 .

Substituindo:

$$
\begin{gathered}
x=4 \\
-x^{2}+25=y \\
-(4)^{2}+25=9
\end{gathered}
$$

Verifica-se, que ao invés do resultado ser igual a nove, deveria ser 3. Então, divide-se por 3, toda equação.

$$
\begin{aligned}
& \frac{-(4)^{2}}{3}+\frac{25}{3}=\frac{9}{3} \\
& \frac{-(4)^{2}}{3}+\frac{25}{3}=3
\end{aligned}
$$

Logo, a lei de formação será dessa parábola será $\frac{-x^{2}}{3}+\frac{25}{3}=0$.

Agora que já se obteve a lei de formação da parábola, deve-se inseri-la na caixa de entrada do GeoGebra. Observa-se que não é possível visualizar a altura exata. Clicar no símbolo

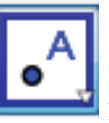

na barra de tarefas encontrada na parte superior do software GeoGebra. Escolher a opção ponto. Na Janela de Visualização, clicar no ponto que intercepta o EixoY. Automaticamente na Janela de Álgebra, aparecerá o ponto com as coordenadas exatas. (Figura 25).

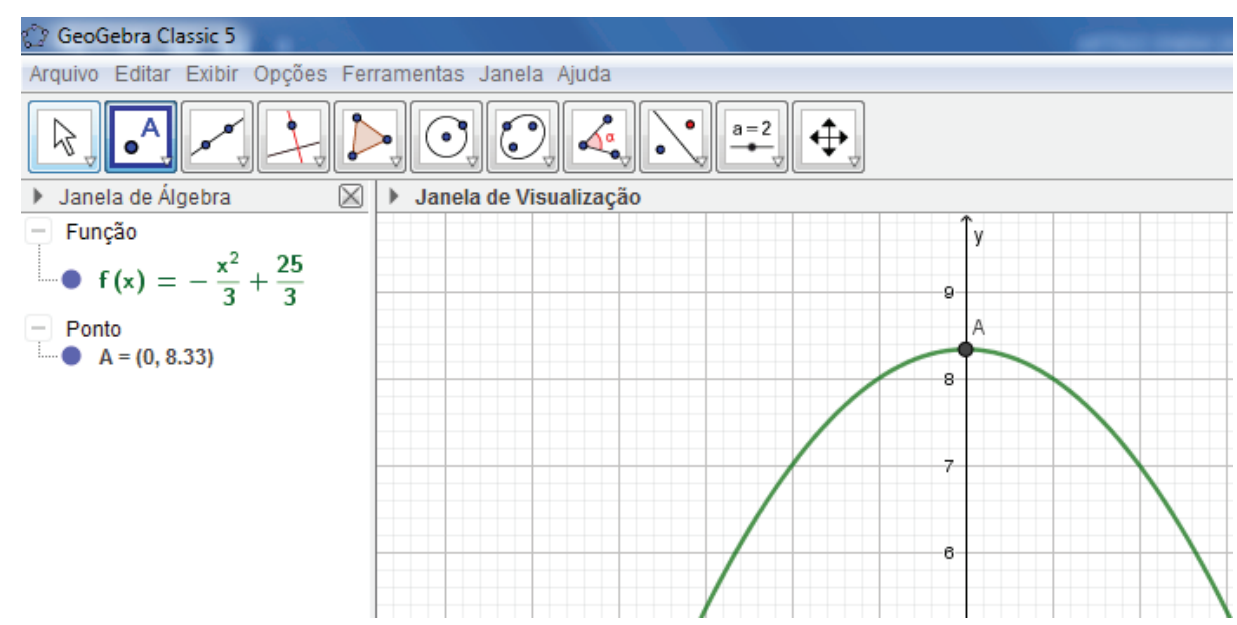

Figura 25: Ponto de intersecção com o EixoY

Fonte: A pesquisa.

O ponto A, informa que a altura da parábola é de $8,33 \cong \frac{25}{3}$. Logo a resposta correta é a 
alternativa D.

\section{Considerações Finais}

O planejamento do professor muda quando utiliza recursos tecnológicos, pois as TIC podem auxiliar servindo como agentes potencializadores para compreensão, pelos estudantes, dos conteúdos do Ensino Médio, que devem ser desenvolvidos pelos professores de Matemática, qualificando o estudante para a realização do Enem.

As tecnologias já são utilizadas pelos alunos, assim, é possível aproximar a realidade dos estudantes com a vida escolar, possibilitando, ainda, tornar as aulas mais dinâmicas. O professor, utilizando tais recursos, pode avançar no aprofundamento de ideias matemáticas de forma muito mais rápida, oportunizando a autonomia dos estudantes e agindo como um orientador do processo de ensino e aprendizagem.

Acredita-se que o professor de Matemática pode incluir no planejamento do processo de ensino e aprendizagem em Matemática aulas que utilizem como recurso softwares como o GeoGebra. Concorda-se com o afirmado pelo NCTM: "O uso eficaz da tecnologia requer um planejamento cuidadoso. Os docentes necessitam um desenvolvimento profissional adequado para aprender a utilizá-las com eficácia” (NTCM, 2015).

\section{Referências}

ALMEIDA, Rafania. Na rede pública, tecnologia atende 24 milhões de alunos. 2016. Disponível em: $<$ http://portal.mec.gov.br/component/tags/tag/33994>. Acesso em 26 mar 2018.

INEP. Exame Nacional do Ensino Médio (ENEM): Fundamentação Teórico-Metodológica. Brasília, DF: 2005.

INEP. Exame Nacional do Ensino Médio (ENEM): Provas e Gabaritos. 2016. Disponível em: $<$ http://portal.inep.gov.br/provas-e-gabaritos $>$. Acesso em 26 mar 2018.

INEP. Exame Nacional do Ensino Médio (ENEM): Provas e Gabaritos. 2017. Disponível em: $<$ http://portal.inep.gov.br/provas-e-gabaritos $>$. Acesso em 26 mar 2018.

COSTA, José Carlos Oliveira; SANTOS, Vinício de Macedo. O Currículo de matemática para o Ensino Médio frente à diversidade de caminhos formativos. In: Educação Matemática-contribuições para as séries finais do Ensino Fundamental e Médio. Organizado por Claudia Lisete Oliveira Groenwald e Marcio Antonio da Silva. Canoas: Editora da ULBRA, 2013.

MURRIE, Zuleica de Felice (coord.). Matemática e Suas Tecnologias: Livro do Estudante: Ensino Médio. Brasília, DF: 2006.

NCTM. De los Princípios a la Acción - para garantizar el êxito matemático para todos. NCTM: 
México, 2015

OLIVEIRA, Claudio de. et al. TICs na educação: a utilização das tecnologias da informação e comunicação na aprendizagem do aluno. Pedagogia em Ação, v.7, n.1, dez. 2015. 